\title{
O ENSINO DO SANEAMENTO - DESAFIOS PEDAGÓGICOS E FORMATIVOS
}

\author{
THE TEACHING OF SANITATION - PEDAGOGICAL AND FORMATIVE CHALLENGES
}

Luciane Dusi ${ }^{1}$

\section{RESUMO}

Este relato trata do ensino do Saneamento no curso de Engenharia Civil da Universidade de Alto Vale do Rio do Peixe - UNIARP. A disciplina tem como objetivo geral capacitar o aluno a compreender o Saneamento em todos os seus componentes, e em específico, no que se refere os seus serviços básicos, que são a disponibilidade de água potável, tratamento de esgoto, gestão dos resíduos sólidos e drenagem urbana. O ensino do saneamento visa formar profissionais que contribuam para o desenvolvimento social, econômico, político e cultural na dimensão local, regional, nacional e internacional. Antes da exposição dos conteúdos técnicos, o método educacional utilizado procura construir o conhecimento dos alunos em relação a amplitude que envolve o conceito de saneamento e a sua finalidade maior que abrange dar condições adequadas à manutenção da saúde das pessoas na cidade, para isto utiliza o mito grego-romano sobre o tema. Adicionalmente às aulas expositivas, são realizadas visitas técnicas às estruturas de saneamento básico de Caçador. Esta é a forma pedagógica de inserção dos futuros engenheiros civis a um aspecto mais complexo do tema, ou seja, quando ele está inserido numa realidade social. Na cidade de Caçador existem serviços sendo prestados nos quatro itens integrantes do conceito de Saneamento Básico, constituindo um bom e rico ambiente educacional.

Palavras-Chave: Saneamento, mito, ensino.

\section{ABSTRACT}

This report deals with the teaching of Sanitation in the Civil Engineering course of the University of Alto Vale do Rio do Peixe - UNIARP. The general objective of the course is to enable the student to understand Sanitation in all its components, and in specific, regarding its basic services, which are the availability of drinking water, sewage treatment, solid waste management and drainage Urban The teaching of

\footnotetext{
${ }^{1}$ Mestre em Engenharia Ambiental pela UFSC. Docente na UNIARP. E-mail: dusiluciane@gmail.com.
} 
sanitation aims to train professionals who contribute to social, economic, political and cultural development in the local, regional, national and international dimension. Before the presentation of the technical contents, the educational method used seeks to build students' knowledge of the breadth of the concept of sanitation and its major purpose, which is to provide adequate conditions for maintaining the health of people in the city. Greek-Roman myth on the subject. In addition to the lectures, technical visits are made to Caçador's basic sanitation facilities. This is the pedagogical form of insertion of future civil engineers into a more complex aspect of the theme, that is, when it is embedded in a social reality. In the city of Caçador there are services being provided in the four items that are part of the concept of Basic Sanitation, constituting a good and rich educational environment.

Keywords: Sanitation, myth, teaching.

\section{INTRODUÇÃO}

Saneamento é um dos temas mais estudados quando tratamos da qualidade ambiental nas cidades. Fato este que se reflete na necessidade de fundamentá-lo como uma disciplina básica em escolas de engenharia, como é o caso do Curso de Engenharia Civil da Universidade do Alto Vale do Rio do Peixe (UNIARP), localizada na região centro oeste do Estado de Santa Catarina.

Para um professor é fundamental pesquisar e se aprofundar sobre a relevância de sua disciplina para a formação do aluno e a sociedade. Ele precisa estabelecer estratégias de ensino que possibilitem a construção do conhecimento pelo aluno. O ensino deve alcançar os elementos relacionados com a importância da disciplina não somente para a carreira profissional do estudante, mas também relacioná-la com sua própria vida e com as necessidades da sociedade. Desta forma, é possível formar alunos de nível superior que estejam aptos a discernir por si mesmos sobre qual ferramenta utilizar no exercício de sua profissão e como utilizá-la.

A intenção deste relato é a de apresentar como o ensino de saneamento pode ser feito de forma inspiradora e factual ao mesmo tempo. Primeiramente, o arranjo metodológico propõe a apresentação do tema aos alunos no seu aspecto mais ideológico, abordando o conceito de saneamento formulado pela Organização Mundial da Saúde (OMS), o qual abrange no seu significado, 
componentes para além daqueles considerados na descrição do Saneamento Básico. Neste aspecto, a disciplina propõe relacionar o tema com a qualidade de vida da população, mostrando que as necessidades para uma vida sadia ao ser humano vão além das estruturas básicas de saneamento e requerem planejamento, arte, ciência e cultura de qualidade. Com a construção desta imagem, os alunos levam consigo não somente o ensino de uma matéria, mas também um ideal ao qual buscar durante o exercício de sua profissão.

Num segundo momento metodológico, visando construir a formação prática e técnica do aluno, a disciplina apresenta os conteúdos técnicos e, concomitantemente a esta apresentação, trata de levar os alunos a campo e proporcionar aos mesmos o contato direto com as estruturas de saneamento básico. Neste caso o objetivo é o de fornecer lhes uma visão prática diante do tema, tornando-os aptos a reconhecer as principais obras relacionadas com o tema, suas dimensões e necessidades de operação e manutenção. As visitas de campo servem como ilustração da teoria apresentada em sala de aula, oferecendo ao estudante um parâmetro de referência onde ele possa sustentar todas as informações e conhecimentos descritos em sala de aula. Este artigo vai abordar mais detalhadamente a forma de aplicação da disciplina, bem como o tema do saneamento.

\section{MATERIAL E MÉTODOS}

Este artigo foi escrito com base nos estudos realizados pela autora para compor a disciplina de saneamento, integrante da matriz curricular do curso de Engenharia Civil da UNIARP. Foram realizadas pesquisas bibliográficas, bem como o material foi repensado e estruturado também em base às experiências de dois anos ministrando a disciplina nesta universidade.

\section{RESULTADOS E DISCUSSÃO}

O ENSINO DO SANEAMENTO NO CURSO DE ENGENHARIA CIVIL

Segundo Livraga (19__), a educação deve prover a cada um dos 
componentes da sociedade - criança, adolescente, jovem, adulto e idoso - com o melhor em suas respectivas idades, dando-Ihes convenientes oportunidades de desenvolvimento. Baseado no que Platão coloca em seu livro "A República", Livraga (19 ) afirma que é necessário cultivar a vocação heróica nos adolescentes, os quais precisam substituir paulatinamente, por meio da iniciativa em ação, sua atitude sonhadora.

Adiante, o jovem deverá estudar e habilitar-se segundo sua própria vocação e capacidades práticas, preparando-se para colaborar com a obra pública, até chegar à idade adulta e participar da sociedade como cidadão.

Tomando esta perspectiva da educação como ponto de partida, vemos a educação técnica como uma ferramenta que serve para capacitar o jovem a construir seus sonhos e torná-los realidade na sua prática quando adultos. Com objetivo de fazer esta ligação entre sonho e realidade, a autora incluiu, no ensino de sua disciplina, um espaço para apresentar e debater o conceito de saneamento apresentado pela Organização Mundial da Saúde - OMS. Adicionalmente, a disciplina propõe aos alunos, em paralelo à exposição dos conteúdos exclusivamente técnicos, conhecerem a realidade do saneamento da cidade de Caçador. Esta é a forma pedagógica de inserção dos futuros engenheiros civis em um aspecto mais complexo do tema, quando ele está inserido numa realidade social.

São realizadas ao longo do semestre três visitas de campo com a turma. Após apresentar em sala de aula a parte teórica sobre a captação, adução, tratamento e distribuição de água potável, é realizada a visita técnica à Estação de Tratamento de Água de Caçador. Nessa visita os alunos podem conhecer as principais estruturas que promovem o tratamento da água, as rotinas operacionais e de segurança e, adicionalmente, obter informações sobre o ponto de captação da água, seu sistema de transporte até à estação de tratamento, os reservatórios de água tratada espalhados pela cidade e o traçado da rede de distribuição de maneira geral. Os alunos acabam também tomando conhecimento dos principais desafios para este setor no município.

Depois, em sala de aula, é trabalhado teoricamente o tema do tratamento de esgoto e, após a exposição teórica, vamos até uma estação de tratamento de esgoto, operada pelo município de Caçador no loteamento Ulisses Guimarães, para 
conhecer a realidade. Nesta visita os alunos vivenciam os desafios nesta área, que começam na rede coletora de esgoto. Na estação, os alunos podem observar as principais estruturas de tratamento, seus requisitos de operação e manutenção.

Depois, ainda conferem o destino do esgoto tratado e do lodo produzido na estação, como subproduto do processo de tratamento. A última visita constante no programa da disciplina é no Aterro Sanitário de Caçador. Da mesma forma como acontece no estudo dos dois temas anteriores, a matéria teórica é apresentada e dialogada anteriormente em sala de aula e depois é realizada a visita. No aterro os alunos podem ter uma noção do tamanho da área deste empreendimento, o conhecimento de solos, estabilidade de taludes, compactação e drenagem que o engenheiro precisa ter para operar esta estrutura de forma adequada. Tudo isto eles podem conferir em campo e terem uma noção mais apurada de como as coisas realmente acontecem.

A seguir o artigo apresentará o conceito de saneamento formulado pela OMS e também o conceito de Saneamento Básico, da forma como são apresentados na disciplina aos alunos.

\section{DEFINIÇÃO DE SANEAMENTO}

O saneamento está relacionado com o surgimento e o crescimento das cidades, que normalmente eram instaladas em locais próximos a um rio, pois em suas múltiplas atividades os seres humanos precisam da água, seja para suprir suas necessidades básicas, ou para cultivar seus alimentos. Alguns exemplos de civilizações que floresceram próximas de rios são a China, no rio Amarelo; o Paquistão, no rio Hindo; a Mesopotâmia, nos rios Tigre e Eufrates; e Egito, no rio Nilo (ROCHA, 2015).

E para manter a ordem e harmonia no ambiente da cidade é necessário o desenvolvimento de regras e de atividades voltadas à manutenção deste espaço. Sendo assim, não podemos excluir da história do desenvolvimento de uma sociedade esta faceta, pois o desenvolvimento econômico e social de forma sustentada requer uma visão mantenedora da ordem e sanidade dos espaços da cidade.

Apesar desta importância inquestionável, infelizmente qualquer grande centro urbano brasileiro ainda convive com dilemas relacionados com a falta de 
saneamento básico. Bem próximo de cidades urbanizadas e bem estruturadas é possível encontrar comunidades e periferias ainda desassistidas de saneamento, um dos direitos que deveria já ter sido universalizado a todos (ARARIPE, 2016).

Uma das definições frequentemente utilizada para saneamento é aquela apresentada pela Organização Mundial da Saúde (OMS). Segundo esta agência, saneamento é o controle de todos os fatores do meio físico do homem, que exercem ou podem exercer efeitos nocivos sobre o bem-estar físico, mental e social (GUIMARÃES, CARVALHO e SILVA, 2007). Então, segundo esta definição, saneamento está relacionado com o controle dos efeitos nocivos que o meio físico pode exercer sobre o homem, efeitos não somente de ordem física, mas mental e social também. Considera-se que uma cidade sem saneamento não provoca somente problemas relacionados com doenças infecciosas, limitações de uso do espaço ou dos recursos naturais, mas também gera efeitos nocivos ao desenvolvimento sadio da inteligência humana, sua capacidade de pensamento, memória e intuição. No que se refere ao aspecto social este diz respeito às relações entre as pessoas, sentimentos, modos de ser, de estar, de agir e de se manifestar.

Se buscarmos a etimologia da palavra saneamento, veremos que ela vem do Latim SANUS, "de boa saúde, sadio". E por sua vez, segundo a OMS, saúde é um estado de completo bem-estar físico, mental e social, e não consiste apenas da ausência de doença ou de enfermidade.

O ser humano requer a manutenção de certos padrões em seu estilo de vida para garantir sua saúde física, mental e social. Esses padrões vão desde aspectos físicos bem definidos - como água tratada, resíduos sólidos e líquidos coletados - até elementos mais sutis - como ambientes belos e equilibrados que possibilitem um bom desenvolvimento mental e uma harmoniosa convivência social. A análise do saneamento do ponto de vista da manutenção da saúde também requer a consideração de um componente importante dentro da sociedade, a sua moral. Moral provém do latim 'mores', que significa costumes. Esta análise trás à questão do saneamento os componentes educacional e cultural promovidos pelo Estado.

O controle dos fatores do meio físico do homem deve ser interpretado como a integração das pessoas às condições do ambiente natural onde está 
inserida. A cidade, para se manter sustentável, precisa compatibilizar a presença humana com a preservação do ambiente natural. Este aspecto ambiental tem sido o enfoque dado por muitas ciências ligadas à aplicação do saneamento, tais como a drenagem, gestão de recursos hídricos, análise de ciclo de vida dos produtos consumidos nas cidades, reciclagem, reuso da água, padrões de tratamento dos efluentes domésticos e industriais, etc.

O saneamento também pode ser abordado do ponto de vista mais elementar, frequentemente denominado como Saneamento Básico. Segundo a Lei Federal 11.445/07, considera-se saneamento básico o conjunto de serviços, infraestruturas e instalações operacionais de (Presidência da República, 2007): a) Abastecimento de água potável: constituído pelas atividades, infra-estruturas e instalações necessárias ao abastecimento público de água potável, desde a captação até as ligações prediais e respectivos instrumentos de medição; b) Esgotamento sanitário: constituído pelas atividades, infraestruturas e instalações operacionais de coleta, transporte, tratamento e disposição final adequados dos esgotos sanitários, desde as ligações prediais até o seu lançamento final no meio ambiente; c) Limpeza urbana e manejo de resíduos sólidos: conjunto de atividades, infraestruturas e instalações operacionais de coleta, transporte, transbordo, tratamento e destino final do lixo doméstico e do lixo originário da varrição e limpeza de logradouros e vias públicas; d) Drenagem e manejo das águas pluviais urbanas: conjunto de atividades, infraestruturas e instalações operacionais de drenagem urbana de águas pluviais, de transporte, detenção ou retenção para o amortecimento de vazões de cheias, tratamento e disposição final das águas pluviais drenadas nas áreas urbanas.

O Saneamento Básico aparece como uma relação de atividades, infraestruturas e regras necessárias para garantir as condições mínimas de saneamento no ambiente das cidades. Assim, é preciso compreender que estes serviços não suprem a necessidade total de saneamento, mas apenas em parte. Seriam os requisitos mínimos a serem atingidos, principalmente aplicados aos países subdesenvolvidos ou em desenvolvimento, situação na qual se enquadra o Brasil.

O que acontece atualmente, no que se refere à realidade brasileira, é que a discussão do saneamento não consegue avançar para além do seu aspecto 
básico.

O conceito de saneamento apresentado pela OMS não é com conceito novo, mas, pelo contrário, muito antigo. Assim como o legado grego e romano formaram a base do nosso sistema jurídico, podemos ver nestas antigas civilizações também aspectos interessantes sobre o saneamento.

\section{AS ANTIGAS CIVILIZAÇÕES E SUA RELAÇÃO COM O SANEAMENTO}

Este tópico foi incluído na condução da disciplina para atingir dois objetivos: resgatar a origem do conceito de saneamento apresentado pela OMS; e apresentar para os alunos o mito greco-romano relacionado com o tema. Desta forma, é apresentada a forma como as culturas gregas e romanas tratavam o tema do saneamento.

A maneira como iremos encontrar o legado sobre o saneamento nas culturas gregas e romanas é, primeiramente, em textos escritos na forma de mitos. Abordar a mitologia por detrás da visão sobre o saneamento na civilização grega e romana possibilita ao pesquisador resgatar a ideia de finalidade que essas culturas tinham sobre esse tema. O que é saneamento e para que ele é necessário?

Os mitos eram escritos para guardar a essência dos ensinamentos e podiam ser acessíveis a toda a população, fazendo com que as principais ideias sobre o saneamento, por exemplo, fossem conhecidas, cultivadas e não fossem esquecidas, mesmo nas rotinas diárias da cidade.

Segundo Joseph Campbell, os mitos contêm informações provenientes dos tempos antigos, que têm a ver com os temas que sempre deram sustentação à vida humana e que construíram civilizações (CAMPBELL, 2016). Mito, do grego, significa narrar, contar. Logia, do grego lógos, significa estudo, palavra, ciência. Mitologia é o estudo das lendas, mitos, narrativas e rituais, com que os povos antigos reverenciavam os deuses e heróis, que por sua vez tinham nas mãos o destino dos homens e regiam o mundo.

Trazer para o universo dos mitos os assuntos relevantes a uma cultura significa dar sentido e finalidade clara às questões para ela importantes. É uma forma de fazer perpetuar esses temas ao longo dos séculos e manter as ações práticas decorrentes dessas finalidades sempre alinhadas com seu objetivo maior. 
Como é bastante comum em mitologia, temos algumas versões um pouco diferenciadas dos mitos.

Nos mitos, os(as) deuses(as) são forças da natureza dotadas de inteligência e vontade. Portanto, os mitos dos deuses são narrativas sobre a Natureza simbolizada pelas diferentes divindades. A lógica da mitologia é mostrar um universo animado em que cada força natural combinada com outra e manifesta tudo o que existe. Na mitologia grega a natureza é ordenada hierarquicamente, assim os deuses também o são. A hierarquia dos deuses, os laços de família e os relacionamentos deles têm o intuito de mostrar como é essa ordenação. Os gregos concebiam três gerações, ou três ciclos, de deuses, sendo que Apolo é filho de Zeus, sendo Zeus um deus de terceira geração (GERVINI, 2017).

Como é bastante comum em mitologia, temos algumas versões um pouco diferenciadas dos mitos. $\mathrm{O}$ mito trabalhado neste artigo será aquele que narra o nascimento de Higeia, a deusa relacionada com o saneamento, que é filha de Asclépio, o deus da medicina.

Segundo Brandão (1987, p. 90), Asclépio era um semi-deus, filho do deus Apolo e de uma mortal, Corônis. O filho de Apolo e Corônis tiveram vários filhos, entre os quais dois médicos chamados Podalírio e Macáon, que aparecem na llíada, e as sempre jovens Panacéia e Higeia. Como se vê, Asclépio de Corônis deram origem a uma constelação em defesa da saúde, dois médicos, uma panacéia e uma higeia.

O fato de Asclépio ser filho de um deus com uma mortal, significa que Asclépio, o pai de Higeia, possuía duas naturezas dentro dele, uma divina e outra humana. Esta narrativa aproxima Asclépio dos seres humanos, pois segundo a tradição grega, o ser humano também possui duas naturezas dentro dele, uma humana e outra divina, e que esta parte divina precisa ser encontrada durante sua vida e trazida a tona.

Asclépio é um Deus que não está no Olimpo nem habita o Hades, mas caminha entre os homens ensinando a medicina e aliviando-os das doenças BRANDÃO (1987, p. 91). Significa que Asclépio, por provar-se útil à humanidade, ajudando-a no seu caminho evolutivo, foi colocado pelos deuses no meio da humanidade, podendo praticar sua sabedoria entre eles.

Asclépius ensinou a sua arte aos seus filhos. Aquela filha que vai trazer a 
relação da saúde com o tema do saneamento, foco deste artigo, é Higeia. Higeia era a deusa da saúde, limpeza e sanidade, ela era associada à prevenção da doença. Era comumente adorada em conjunto com seu pai, enquanto Asclépio era diretamente associado à cura, Higeia estava relacionada com a continuidade da boa saúde BRANDÃO (1987, p. 91). O primeiro aspecto que vemos quando o mito fala de Higeia é da sua relação com a prevenção e manutenção da saúde e do seu parentesco familiar com o deus da medicina. Vejamos que não é difícil para nós compreendermos o contexto que o mito apresenta, pois o saneamento justamente é o aliado do sistema hospitalar no que se refere a manutenção da saúde das pessoas. O saneamento é esta componente da gestão do Estado que trabalha no sentido de evitar o pior, evitar a doença.

Asclépio na Antiga Romana foi relacionado ao sol, enquanto Higéia seria a lua BRANDÃO (1987, p. 91). A Lua simboliza os ritmos biológicos, e as fases da vida, pois ela passa regularmente por um ciclo de vida, uma vez que é um astro que cresce, diminui, desaparece e cresce novamente. O Sol simboliza a luz, o amor, a vitalidade, o conhecimento, a juventude, o fogo, o poder, a força, a perfeição. Sendo assim, Higeia representa bem a vida humana, seus ciclos diários e necessidade de mante-los em harmonia para que o equilíbrio permaneça.

Higeia era cooperativa e cuidadosa, gostava de agir com perfeição BRANDÃO (1987, p. 91). As virtudes que vemos no mito associadas a Higeia podem servir de inspiração para a forma com que o saneamento precisa ser tratado na cidade. Cooperação e agir com perfeição. As estruturas de saneamento básico, por exemplo: os sistemas de abastecimento de água, de coleta e tratamento de esgoto, coleta e destino dos resíduos sólidos e a drenagem urbana são atividades de operação contínua, funcionam com a rigorosidade industrial, e exigem manutenção preventiva para que não ocorra nenhum problema que possa gerar transtornos aos cidadãos. Mas, diferente da indústria, que está implantada uma área mais restrita, as estruturas de saneamento estão espalhadas por toda a cidade e cada um dos cidadãos "trabalha" em alguma parte do processo, seja fazendo uma adequada ligação na rede de esgoto, separando o lixo ou limpando seus terrenos para evitar o acumulo de lixo ou inundações. Será que estas virtudes podem ser úteis para nos inspirar na forma como fazemos o saneamento atualmente? Vejam que não estamos falando de recursos financeiros, foco principal de todas as críticas sobre o 
tema, mas estamos falando de atitudes humanas que podem trazer mais eficiência e eficácia ao processo.

As estátuas de Higeia mostram uma jovem e bela mulher alimentando uma enorme serpente que circunda seu corpo com uma pátera (taça, jarra ou tigela) BRANDÃO (1987, p. 91). A cobra é o símbolo da sabedoria e da perfeição divinas e tem representado a regeneração psíquica. Fazendo uma relação com as infra-estruturas construídas para o saneamento, elas deveriam representar seu poder de regeneração para a cidade. Estas estruturas não deveriam carregar o olhar de repulsa com o qual as vemos hoje, se fossem bem mantidas, poderiam representar o trabalho de limpeza diário que é necessário ser feito para manter a ordem e sanidade na cidade. Geralmente são ambientes insalubres, mas quem disse que precisa ser assim? Será que eles seriam assim se aplicássemos as virtudes indicadas no mito para a sua gestão? Os resíduos fazem parte da atividade não somente humana, mas de toda a natureza. O problema não está no fato de que eles existem, mas da forma como os tratamos, desde de sua origem, até destino final.

O culto de HIgeia como uma deusa independente só começou a ser divulgado depois da devastadora praga que atingiu Atenas em 429 e 427 a.C. Em Roma seu culto começou em 293 a.C. também após uma epidemia. Seus templos primários eram em Epidauro, Corinto, Cós e Pérgamo. Podemos perceber a relação direta da deusa com as pragas KOCH (2012). Para além do seu significado espiritual, o culto a deusa também influenciava o comportamento das pessoas e ajudava a sanar os problemas epidemiológicos.

Arífron, artista de Sícion do século IV a.C, escreveu um hino bem conhecido para celebrá-la. Estátuas de Higeia foram criadas por Escopas, Briáxis e Timóteo, entre outros. Ela era freqüentemente representada como uma jovem alimentando uma grande serpente enrolada em torno de seu corpo. Às vezes, a serpente bebia de uma jarra que ela levava. Esses atributos foram mais tarde adotados pela deusa galo-romana da cura, Sirona KOCH (2012).

A Hígia grega possui seu equivalente na mitologia romana, Sallus, representada por Cloacina (latim, cloaca: "esgoto" ou "fuga"), também vista como uma das faces de Vênus. Esta representação da deusa presidia as funções purificadoras da cidade e uma estátua de Cloacina foi erigida sobre a Cloaca 
Máxima ("Grande dreno"), o tronco principal do sistema de esgotos de Roma. A estátua ficava diante do Fórum Romano referenciava o espírito da "Grande fuga", constituindo num pequeno Santuário de Vênus Cloacina. Algumas moedas romanas tinham imagens de Cloacina ou de seu santuário numa de suas faces. Um poema foi escrito para Cloacina (BATISTELLA, 2016), representando uma prece para que cuidasse do fluxo de limpeza da cidade:

Ó Cloacina, Deusa deste lugar,

Olhe sobre os suplicantes com um rosto sorridente.

Suave, mas coesa, deixa suas ofertas de fluxo,

Não precipitadamente rápidos nem com insolência lentos.

\section{AS OBRAS DE SANEAMENTO EM ROMA}

A proposta agora é de apresentar algumas obras de saneamento realizadas pela civilização romana. O império romano se expandiu pela Europa Ocidental e Meridional, a Ásia Menor, o Norte da África e partes da Europa Setentrional e Oriental. Uma das formas de se comprovar a magnitude desta civilizações é pela observação de suas obras.

O aqueduto talvez seja a mais característica de todas as estruturas romanas - era construído para levar água em grande quantidade às cidades, para ser bebida, para as termas públicas e privadas, para uso ornamental em lagos e fontes, e possivelmente também para irrigação de terras e vilas rurais. De longas distâncias, as águas de nascentes e de rios eram coletadas e canalizadas, parcialmente por túneis subterrâneos, parcialmente por canais apoiados sobre paredões a arcos, até chegar a um reservatório, de onde tinha início a sua distribuição à cidade.

O traçado de um aqueduto era planejado de modo muito similar ao que se usa em nossos dias para estudar a implantação de uma estrada de ferro, sendo seu curso às vezes consideravelmente prolongado (GIOVANNONI, 1992).

Durante o império romano, foram abertos túneis nas montanhas, alguns com quase 2,5 quilômetros de comprimento, como o que vai do elevado vale do Líris em direção ao antigo Angitia. As estruturas de alvenaria construídas através dos vales tinham às vezes escala tão importantes quanto a de pontes largas, como 
no aqueduto de Segóvia e muitos outros na Espanha. A superposição dos canais de mais de um aqueduto frequentemente lhes dava uma aparência particularmente imponente, como no caso da Porta Maggiore, em Roma (GIOVANNONI, 1992).

Os aquedutos não eram permanentemente impermeáveis, porque o opus signinum que revestia as paredes internas do canal estava sujeito a danos. Ao contrário de qualquer outra construção romana, estas estruturas exigiam reparos e reconstrução contínuos e o abandono de manutenção regular significava que automaticamente cessariam de funcionar (GIOVANNONI, 1992).

O sistema de condutos sob pressão não era o sistema comum dos romanos, mas foi empregado em alguns casos importantes. Utilizavam tubos de metal (geralmente chumbo), terracota ou madeira e alvenaria. Exemplos de utilização do sistema de sifão no trânsito pelos vales, embora não constatados nos aquedutos próximos a Roma, são bastante comuns em outros lugares. O fluxo regular de água aos muitos locais onde ela era necessária foi garantido por um complexo sistema de canos de chumbo, de cisternas cilíndricas também de chumbo - acionados por pressão ou por nível ilimitado - de torneiras, de subdivisões com portas etc (GIOVANNONI, 1992).

Os reservatórios eram diretamente vinculados ao sistema do aqueduto. Possuíam às vezes enorme capacidade, como a piscina Mirabilis de Bacoli, que cobria uma área de quase $2.000 \mathrm{~m} 2$. No que se refere aos grandes diques retentores de água, o de Subiaco consistia de uma parede de $14 \mathrm{~m}$ de espessura, transposta por uma ponte de cerca de $40 \mathrm{~m}$ de altura, formando um longo lago que entrava aproximadamente dois quilômetros vale adentro. Sua finalidade principal era a de ornamentar a Vila de Nero (GIOVANNONI, 1992).

Os romanos herdaram sua técnica de drenagem dos pantanosos distritos e lagos dos etruscos. A drenagem e o controle dos lagos através de canais de escoamento foram a realização mais importante nesta área da engenharia romana (GIOVANNONI, 1992).

Com essas informações podemos considerar que no império romano havia atenção e recursos de saneamento, os quais exigiam manutenção e também serviam de ornamento, trazendo beleza às cidades. Após passar pelas culturas grafas e romanas, é necessário retornar a época atual e fazer um relato geral de como é a situação do saneamento hoje no Brasil, bem como levantar dados locais 
aos alunos. As informações atuais trazem embasamento para formulação do pensamento crítico e construção da postura do aluno diante do tema.

\section{DADOS DA SITUAÇÃO DO SANEAMENTO HOJE NO BRASIL}

No Brasil, segundo o Sistema Nacional de Informações sobre Saneamento (SNIS), em seu último Diagnóstico dos Serviços de Água e Esgoto realizado em 2013, 93,0\% da população urbana é atendida por rede de abastecimento de água e somente $56,3 \%$ é atendida com coleta de esgoto e destes, somente $39,0 \%$ sofre algum tipo de tratamento. Nesse cenário, mais de $60 \%$ do esgoto doméstico gerado no Brasil é lançado in natura nos corpos d'água e os outros quase $40 \%$ passam por tratamento, numa tentativa por parte dos prestadores dos serviços de enquadrarem os efluentes às legislações federal e/ou estadual (SOUZA; SANTOS, 2016). Atualmente o País ocupa a 10a posição em coleta de esgoto quando comparado a outros 17 países da América Latina. O Brasil fica atrás de países como Venezuela, Equador, Peru e Bolívia (SANEAMENTO BÁSICO: INVESTIMENTO SOCIAL DE ALTO IMPACTO, 2016).

O setor de saneamento básico no Brasil, entre as ações de infraestrutura urbana, sempre foi relegado a segundo plano. Em 2014 foi aprovado o Plansab Plano Nacional de Saneamento Básico, com a finalidade de estabelecer um planejamento de longo prazo para o setor, prevendo o volume total de recursos necessários à universalização, da ordem de R\$ 504 bilhões (FILHO, 2016). No entanto, o processo de universalização não está sendo executado de acordo com as metas do Plansab, nem na velocidade desejada. Segundo balanço do Ministério das Cidades, no período de 2007 a 2015 foram selecionados R\$ 86,1 bilhões, contratados $\mathrm{R} \$ 81,5$ bilhões e executados $\mathrm{R} \$ 38,1$ bilhões em obras de saneamento. Ou seja: os operadores públicos e privados só conseguiram executar $46,7 \%$ de todo o valor contratado para o setor (FILHO, 2016). Se persistir nesse ritmo, as metas estipuladas em 2013 no Plano Nacional de Saneamento Básico não serão atingidas. A meta do Plansab é de chegar à universalização dos serviços de água e esgoto em 2033, porém o ritmo de avanço é tão lento que coloca a meta da universalização para 2052 (SANEAMENTO BÁSICO: BRASIL LONGE DE ATINGIR UNIVERSALIZAÇÃO, 2016).

Os especialistas comentam que o setor carece de mecanismos de 
cooperação entre os entes federados. Diferentemente de outras áreas da infraestrutura, onde a participação do Governo Federal é mais firme e consolidada, no caso do saneamento, a titularidade do serviço é municipal, todavia há uma concentração de companhias estaduais como prestadores do serviço de água e esgoto e a relação entre os entes federados é complexa (Saneamento: Investimento Social de Alto Impacto, 2016).

O saneamento básico no Brasil não condiz com a posição do país no ranking econômico mundial. No semiárido brasileiro 450 mil crianças não têm banheiro na escola. O despejo diário de esgotos na natureza corresponde a aproximadamente o volume de 5 mil piscinas olímpicas. Em 2013, 407 mil pessoas foram internadas por diarreia e doenças decorrentes da falta de saneamento e $53 \%$ dos casos eram crianças de 0 a 5 anos. Isso demonstra um impacto negativo no futuro do país, especialmente nas áreas de saúde, educação e produtividade. Já nas cidades com maior proporção da população com acesso à rede de esgoto, as internações por doenças infecciosas são menores, a renda média das pessoas e o valor médio dos imóveis é maior, bem como os ganhos com o turismo são ampliados. (SANEAMENTO BÁSICO: INVESTIMENTO SOCIAL DE ALTO IMPACTO, 2016).

De acordo com dados das Pesquisas Nacionais de Saneamento Básico realizadas pelo Instituto Brasileiro de Geografia e Estatística - IBGE (2010, apud MANNARINO, FERREIRA, GANDOLLA, 2016) do total de unidades de destinação final de resíduos sólidos no Brasil, apenas 1,1\% eram aterros sanitários em 1989. No ano 2000, 17,3\% dessas unidades eram aterros sanitários e, em 2008, 27,7\%. Segundo a Associação Brasileira de Empresas de Limpeza Pública e Resíduos Especiais - ABRELPE (2014, apud MANNARINO, FERREIRA, GANDOLLA, 2016), no ano de $2013,42 \%$, em peso, dos resíduos sólidos urbanos coletados no Brasil eram dispostos em locais inadequados como lixões e aterros controlados, causando impactos ambientais no solo, nas águas, no ar e na saúde pública. As melhorias na destinação final dos resíduos sólidos urbanos são lentas e estão ocorrendo de forma concentrada nas regiões metropolitanas e nas grandes cidades do país. Uma pesquisa realizada no ano de 2013 indicou que 62\% dos municípios brasileiros possuem iniciativas de coleta seletiva, sendo essas predominantemente encontradas em municípios com mais de 100 mil habitantes. 0 estudo ressaltou 
que, em muitos casos, tais iniciativas se resumem à existência de pontos de entrega voluntária de resíduos ou convênio com cooperativas de catadores e que, em muitos municípios, as atividades de coleta seletiva não abrangem a totalidade de sua área urbana, segundo Abrelpe (apud MANNARINO; FERREIRA; GANDOLLA, 2016).

Após ter ilustrado a situação do saneamento no Brasil, é importante retratar a realidade específica do município de Caçador, tendo em vista que a disciplina se desenvolve neste local e que o contexto prático do tema é trabalhado nesta realidade social.

\section{O SANEAMENTO BÁSICO EM CAÇADOR}

Como está estruturado o saneamento em Caçador? Começando pelo abastecimento de água, o Rio do Peixe é o principal manancial, com área de bacia de contribuição de $247,89 \mathrm{~km} 2$. Os rios Caçador e Castelhano são mananciais alternativos, porém com uma vazão de consumo menor. Adicionalmente são utilizados oito poços de fratura de basalto, sendo as fontes hidrogeológicas um importante recurso hídrico a ser considerado no município (NOTUS, 2014).

O serviço de abastecimento de água é prestado através da Gestão Associada entre Prefeitura Municipal e o Governo do Estado, através da CASAN Companhia Catarinense de Águas e Saneamento. O sistema foi implantado pela Fundação SESP, hoje FUNASA, por volta de 1970. A SESP operou o sistema até meados daquela década, quando foi assinado contrato com a CASAN. Desde 1976 a CASAN operou e executou ampliações no sistema original. Todavia, em 2009 foram iniciadas obras de ampliação da ETA, até agora não concluídas. O sistema cobre pouco menos de $90 \%$ da população urbana (NOTUS, 2014).

Segundo pudemos constatar em nossas visitas técnicas, a estação de tratamento de água se encontra no limite de sua capacidade operacional, necessitando de concretizar o projeto de sua ampliação. Parte das obras necessárias a ampliação já foram executadas todavia nos foi informado que as estruturas possuem problemas técnicos que as impedem de serem colocadas em operação.

O Município dispõe de sistema público de esgotos sanitários com tecnologia alemã em operação no loteamento Ulisses Guimarães, atendendo 
também os bairros Santa Terezinha e COHAB II. Mais dois sistemas, compostos por fossa séptica no Bairro Santa Catarina e fossa séptica e filtro anaeróbio no bairro Bom Sucesso, são operados pelo município. Todos os sistemas são operados sem cobrança de tarifa. Os sistemas beneficiam uma população de 3.068 habitantes, correspondendo a 4,61\% da população urbana do município. No restante da área urbana do município, predominam as soluções individuais. Existem atualmente no mínimo 3 projetos de sistema se esgoto sanitário para Caçador (NOTUS, 2014). Em visitas técnicas realizadas na estação de tratamento do loteamento Ulisses Guimarães, pudemos constatar a necessidade de investimentos para que a estação seja adequadamente operada. Tem-se a necessidade de instalação de um medidor de vazão, faltam instrumentos para a realização do monitoramento operacional e a campanha realizada para educar a população beneficiada sobre como utilizar o sistema não foi suficiente, ocorrendo rotineiramente a introdução de resíduos sólidos e de águas de drenagem na rede coletora de esgoto.

Os serviços de coleta, transporte e disposição final de resíduos sólidos domiciliares são prestados pela empresa Meioeste Ambiental, contratada pelo município. A disposição final dos resíduos é feita em aterro sanitário. A mesma empresa opera a coleta dos resíduos recicláveis, cuja separação e comercialização é feita pela cooperativa COOCIMA. O aterro sanitário, em substituição ao antigo "lixão", começou a operar em agosto de 2004 e está inserido na sub-bacia do Ribeirão Polidoro (NOTUS, 2014).

Em termos de responsabilidade legal pelos serviços de manejo, coleta, transporte e destino final dos resíduos sólidos, esta é da FUNDEMA no que se refere a: resíduos domiciliares, recicláveis, resíduos de poda e jardinagem e de limpeza pública. Já a responsabilidade legal pelos resíduos sólidos dos serviços de saúde é da Secretaria da Saúde, a qual gerencia os serviços públicos e fiscaliza também os estabelecimentos privados de saúde (NOTUS, 2014). Na prática, a FUNDEMA executa diretamente os serviços de varrição, capina, roçagem, poda e jardinagem de áreas públicas. A empresa terceirizada Meioeste faz a coleta dos resíduos domiciliares, a disposição final em Aterro Sanitário e a coleta seletiva. A triagem dos resíduos coletados na coleta seletiva é feita pela COOCIMA e a coleta e destinação dos resíduos sólidos de saúde é feita pela empresa Tucano Obras e Serviços (NOTUS, 2014). 
Em visitas técnicas realizadas com os alunos ao aterro sanitário de Caçador, pudemos constatar que existem deficiências em relação a manutenção dos serviços operacionais necessários à adequada operação do mesmo. A questão gira em torno da necessidade de técnico responsável e dos custos inerentes a sua adequada gestão. Em relação aos resíduos da construção civil, estima-se que o município produza 4.848 toneladas por ano, todavia o município não conta com um plano de gerenciamento de resíduos sólidos da construção civil (NOTUS, 2014).

A secretaria de infraestrutura é responsável pela execução das obras e manutenção da drenagem urbana. Para grandes obras neste setor, o município contrata empresas terceirizadas. Não há cadastro técnico das redes nem rotina para manutenção das redes, galerias e outros componentes do sistema de drenagem (NOTUS, 2014). Dentro do perímetro urbano de Caçador, são dez os córregos principais que formam o sistema de macrodrenagem: DER, Nhozinho, Cemitério, Figueroa, Berger, Martelo 1, Martelo 2, Rancho Fundo, Gioppo e Nossa Senhora Salete. Em 2014, após uma intensa precipitação pluviométria ocorrida no dia 11 de janeiro, a maior desde 1961, ocasionando alguns pontos de alagamento e inundação, o Município tomou a decisão de elaborar um plano diretor de drenagem. Atualmente o município conta com projeto básico para solução dos problemas mais graves da área urbana que são o córrego do DER e o córrego Nhozinho (Santelmo) (NOTUS, 2014).

Após conhecer um pouco sobre o conceito e a história do saneamento, sua situação no Brasil e em Caçador, torna-se importante refletir sobre tudo o que foi exposto; para isto, a experiência de 18 anos da autora na área de saneamento será utilizada.

\section{REFLEXÃO ENTRE A VISÃO ANTIGA E A MODERNA}

Agora é o momento de fazer uma comparação entre a forma de conceber o saneamento nas culturas gregas e romanas e a forma da nossa cultura atual. Este exercício pode ser útil para ajudar a identificar os motivos pelos quais, para nossa cultura, seja tão desafiador lidar com o tema. Apesar de termos tecnologia muito superior à daquelas culturas, ainda carecemos de ver o saneamento implantado de forma plena em nossas cidades. Parece que, dentre outros fatores, não conseguimos gerenciar adequadamente nosso conhecimento humano e os 
recursos financeiros destinados a implantação, operação e manutenção das obras de saneamento; adicionalmente, nossa população cresce de maneira progressiva, complexificando as suas necessidades, e os entes públicos não conseguem se coordenar adequadamente.

A autora desse artigo teve experiências relevantes em relação a esse assunto pelo seu trabalho de 18 anos na área de saneamento. Em 1998 iniciou trabalhando com a coleta de lixo municipal, depois trabalhou com pesquisa científica, projetos ambientais em Organizações Não-Governamentais, licenciamento e fiscalização ambientais na Fundação Estadual de Meio Ambiente de Santa Catarina - FATMA, consultoria ambiental, palestras e docência em universidades. Nestes 18 anos de experiências, ela pôde constatar que por trás das dificuldades gerenciais e financeiras dos projetos nos quais esteve envolvida, existe um aspecto humano que interfere de forma preponderante nos trabalhos e que, via de regra, limita os resultados esperados dos projetos.

Do ponto de vista da engenharia, é difícil justificar que recursos técnicos e financeiros não sejam suficientes para lidar com a questão. Assim, é preciso lançar mão de uma análise mais ampla e aprofundada sobre o tema, de modo a chegar mais perto das raízes das dificuldades culturais e sociais envolvidas. Depois de aproximadamente 8 anos estudando também filosofia e se aprofundando na história e sabedoria das civilizações antigas, a autora propõe um ponto de vista diferenciado para essa questão.

Via de regra, aqueles que trabalham com a área de saneamento e meio ambiente, a qual comporta diversos ramos e especialidades de formação, acabam mergulhados num sentimento de impotência, que se transforma numa atitude crítica e conflitiva diante dos trabalhos. É muito comum surgirem discussões insolucionáveis entre os técnicos, as autoridades governamentais, os empresários e a sociedade em geral. Percebe-se que cada setor parece ter suas próprias necessidades, o que acaba por enfraquecer os projetos. Pode-se até mesmo identificar divergências entre as pessoas participantes de um mesmo setor, pois cada uma parece ter sua própria visão e finalidade com os projetos. "Finalidade": esta é a palavra e o significado que acabaram se perdendo no momento atual. Para qual finalidade está se trabalhando na questão do saneamento? A finalidade técnica, governamental, empresarial ou social? Quais desses setores, aqui 
colocados como exemplo, têm maior importância para assumir o posto de finalidade numa questão relacionada com o saneamento? A resposta a esta pergunta é todos. Todos esses setores mencionados e os demais setores da sociedade são a finalidade, pois o saneamento visa sanear a cidade para que todos possam, em conjunto, desenvolver as suas atividades.

Como foi visto anteriormente, o saneamento é um elemento fundamental para uma civilização, tanto o é que foi retratado na mitologia de duas grandes culturas embasadoras do mundo ocidental moderno. Ocorre que estas civilizações trataram do assunto de forma especial, não o associando diretamente ao interesse deste ou daquele setor, pois pertencia ao interesse de todos e por isso foi delegado aos cuidados dos deuses. Cabia aos setores da sociedade se alinharem de acordo com este compromisso maior. Adaptando a linguagem antiga para a nossa cultura atual, é o mesmo que dizer que existe um objetivo superior aos objetivos específicos de cada setor ou pessoa. Este objetivo superior seria a grande finalidade do saneamento para uma civilização. Esta relação com a finalidade teria que ser resgatada como o ponto de unificação das ações de cada setor e o requisito de avaliação do sucesso de um projeto. Obras de infraestrutura em saneamento são os meios necessários para operacionalizar a finalidade que é o saneamento. E não se trata somente de obras, mas também de educação e de harmonização dos espaços urbanos com jardins e esculturas, como as que fizeram os gregos e romanos. Porque todos estes são os meios pelos quais se promove o saneamento de uma cidade na sua forma completa, necessária à sadia qualidade de vida dos seres humanos. Não está em questão se esses meios são necessários ou não, se são mais ou menos importantes que outras questões do Estado, simplesmente são meios que garantem as bases de uma sociedade e por isso deveriam estar fora do âmbito de discussão promovê-los ou não.

Dada a natureza universal do tema, também fica claro que não é possível um ou outro setor apoderar-se das finalidades dos meios, tendo em vista que estes são voltados para o benefício do todo. O benefício das partes deve ser obtido como consequência intrínseca da implantação dos meios, mas não como finalidade específica deles. Por que atualmente temos grande deficiência no saneamento básico e uma certa alienação do tratamento da questão no seu aspecto mais completo? Talvez porque tenhamos nos afastado da hierarquização entre 
finalidades e meios. Utilizamos os meios - que são as obras, a educação e o harmonização dos espaços, por exemplo - com o fim neles mesmos. Tratamos a água para servir àquele setor, coletamos esgoto para beneficiar outro setor, educamos os jovens apenas para cumprir com um plano de ensino e construímos praças para valorizar os imóveis pertencentes àquele grupo. Esquecemos da finalidade maior, os meios não existem por eles mesmos, mas sim para atingir uma finalidade maior, que no caso do saneamento é garantir a saúde física, psíquica e mental da população.

O livro "Gestão estratégica do saneamento", do professor Ary Haro dos Anjos Júnior (2011), aponta que o Brasil dispõe de uma boa base de conhecimentos técnicos e de especialistas competentes nos mais diversos campos do conhecimento. Mas a articulação desses saberes no contexto da vida urbana ainda é uma deficiência - a qual se torna ainda mais evidente no caso dos projetos de saneamento. Os gestores do setor tomam decisões que afetam, simultaneamente, a saúde pública, o planejamento urbano, o meio ambiente, e a realidade social. Além disso, suas decisões provocam impactos tanto em longo prazo, da ordem de décadas, como em curto prazo, 24 horas ou em até menos tempo. O "apagão da água" é uma ameaça sempre presente, por exemplo. Conforme afirma o autor, os responsáveis pela área necessitam compreender, antes de tudo, a multidisciplinaridade da sua missão, das suas tarefas, e dos seus resultados. E precisam de ferramentas adequadas para definir essa missão, executar as tarefas e medir os resultados das suas decisões (AISSE, 2016).

Este é um ponto de vista que pode ser utilizado para retratar a questão, que certamente não é o único, mas traz alguma luz à questão e permite um avanço na sua análise. É importante formar pessoas que se relacionem novamente com a finalidade do saneamento. Que não somente se sintam parte beneficiada, mas que se orgulhem em garantir um ambiente adequado para a vida das pessoas, contribuindo para manutenção de sua saúde e seu desenvolvimento humano. A qualidade dos projetos desenvolvidos com pessoas desta forma comprometidas aparece inevitavelmente, pois um trabalho feito com boa vontade tem como fruto a eficácia. Grandes obras necessitam de grandes homens no comando de seu planejamento, implantação, operação e manutenção. 
O DESAFIO DOS FUTUROS ENGENHEIROS CIVIS

De acordo com o que foi apresentado anteriormente sobre a realidade da situação do saneamento no Brasil e em Caçador, podemos constatar que os futuros engenheiros civis a serem formados pela UNIARP se depararão com desafios que Ihes exigirão boa vontade e criatividade para serem superados.

$\mathrm{Na}$ cidade de Caçador existem serviços de saneamento sendo prestados nos quatro itens integrantes do seu conceito básico. Dos serviços envolvidos, temos a coleta, o tratamento e a destinação final do esgoto tratado como sendo aqueles que carecem de maior atenção. Todavia, numa avaliação em relação a situação do país, principalmente no que se refere a coleta e destinação final dos resíduos sólidos, a situação de Caçador é boa, principalmente considerando que é um município com menos de 100.000 habitantes. Todavia, em relação ao conceito mais amplo de saneamento, ainda é preciso avançar bastante. Esta realidade do município coloca os alunos em contato com situações que encontrarão na sua vida cotidiana como engenheiros. Projetarão casas, prédios, rodovias e outras obras de engenharia que necessitarão ser integradas aos sistemas de distribuição de água, coleta de esgoto, de lixo e de drenagem. Como fazer isso de forma adequada? Como agirão frente às situações encontradas nas realidades que trabalharão?

Primeiramente espera-se estar conscientizando estes jovens sobre os desafios gerais que fazem parte da realidade brasileira no que se refere ao tema do saneamento. Também são importantes a conscientização e a motivação para fazerem um bom trabalho nesta área, apesar das dificuldades do contexto, resgatando uma visão mais elevada do saneamento utilizada em grandes civilizações. Em última instância, a experiência de ir a campo e se deparar com a realidade e poder voltar para a sala de aula e falar sobre o que viram é uma oportunidade para ajudá-los a construir uma visão menos conflitiva e mais integradora sobre os problemas encontrados.

\section{CONSIDERAÇÕES FINAIS}

O saneamento é uma questão fundamental para a construção de uma sociedade harmônica, com condições de desempenhar bem seus inúmeros papéis. Desde épocas muito antigas este é um assunto conhecido. 
A inclusão da Disciplina de Saneamento no Curso de Engenharia Civil colabora para o desenvolvimento deste conhecimento, promovendo a formação de engenheiros cidadãos capacitados a trabalhar na área.

O município de Caçador possui uma infraestrutura propícia ao estudo de caso sobre o tema, considerando que possui obras para que os alunos possam vivenciar o assunto.

Os desafios em relação ao saneamento ainda são grandes, principalmente se colocarmos como finalidade a mesma visão sobre o tema que tiveram civilizações modelos como a grega e a romana.

É para construir uma realidade futura melhor que trabalhamos na educação dos novos engenheiros civis que se formarão na UNIARP; para que sejam melhores e mais capacitados, tendo em vista que enfrentarão situações também desafiadoras no futuro, trabalhando em sua profissão.

\section{REFERÊNCIAS}

ANJOS JUNIOR, Ary Haro dos. Gestão estratégica do saneamento. Eng. Sanit. Ambient., Rio de Janeiro, v. 16, n. 3, p. iv, Sept. 2011 . Disponível em: $<$ http://www.scielo.br/scielo.php?script=sci_arttext\&pid=S141341522011000300002\&lng=en\&nrm=iso>. Acesso em: 25 jul. 2016.

ARARIPE, S. Saneamento, direito básico de todos. Portal Tratamento de Água. Publicado em 22/03/2016 às 09:57:28. Disponível em: http://tratamentodeagua.com.br/saneamento-direito-basico-de-todos>. Acesso em: 28 jul. 2016.

BATISTELLA, C. O território e o processo saúde-doença. Saúde, doença e cuidado: complexidade teórica e necessidade histórica. Disponível em: $<$ http://www.epsjv.fiocruz.br/pdtsp/index.php?id=3\&prioridade=3>. Acesso em: 01 jul. 2016. BRANDÃO, J de S. Mitologia grega. Petrópolis: Vozes, 1987. V. 2.

CAMPBELL, J. O poder do Mito. O Mito e o Mundo Moderno. [s.I.]: Palas Atena. Disponível em: <http://www.culturabrasil.org/o_poder_do_mito.htm>. Acesso em: 12 jul. 2016.

FILHO, A. de O. Saneamento: Após nove anos da implantação da Política Nacional de Saneamento Básico - O que mudou? Saneamento Ambiental. São Paulo. 
20/01/2016. Disponível em: <http://www.sambiental.com.br/noticias/ap\%C3\%B3snove-anos-da-implanta\%C3\%A7\%C3\%A3o-da-pol\%C3\%ADtica-nacional-desaneamento-b\%C3\%A1sico-\%E2\%80\%93-o-que-mudou>. Acesso em: 22 jul. 2016.

GERVINI, R. Noções Básicas de Mitologia. Florianópolis, 2017. Curso EAD. Disponível em:<http://www.rosangelagervini.com.br/moodle/course/view.php?id=6> Acesso em: 04 jan. 2017.

GIOVANNONI, G. Construção e Engenharia. In: BAILEY, C. O legado de Roma. Rio de Janeiro: Imago, 1992. p. 481-528.

KOCH, S. R. Os santuários de Asclépio: expressões arquitetônicas, sociais e religiosas nos séculos V, IV e III a.C. Dissertação USP. São Paulo, 2012. Disponível em:< file://Users/luciane/Downloads/DISSERT_revisada_Scheila\%20(3).pdf> Acesso em: 03 fev. 2017.

LIVRAGA, J. A. Curso de Filosofia a maneira clássica. Apostila da disciplina intitulada Sociopolítica do primeiro nível do Curso de Filosofia à Maneira Clássica da Associação Cultural Nova Acrópole,19.

MANNARINO, C. F.; FERREIRA, J. A.; GANDOLLA, M. Contribuições para a evolução do gerenciamento de resíduos sólidos urbanos no Brasil com base na experiência Européia. Engenharia Sanitária e Ambiental. v. 21, n.2, Rio de Janeiro, abr./jun. 2016. Epub Junho 20, 2016. Disponível em:

<http://www.scielo.br/pdf/esa/2016nahead/1809-4457-esa-

S1413_41522016146475.pdf>. Acesso em: 22 jul. 2016.

NOTUS. Serviço de Engenharia S/C Ltda. Versão final do Plano de Saneamento Básico de Caçador - PMSB. Florianópolis, 2014. Presidência da República. Lei n. 11.445 de 5 de janeiro de 2007. Disponível em:

<http://www.planalto.gov.br/ccivil_03/_ato2007-2010/2007/lei/l11445.htm>. Acesso em: 25 jul. 2016.

ROCHA, Aristides Almeida. Seminário Segurança da água para consumo humano CEAP/FSP e ABES. Palestra Saneamento no Brasil, trajetória, história e crise atual. 07 de maio de 2015. Disponível em: <http://www.abessp.org.br/arquivos/ARISTIDES_ROCHA_Saneamento_Brasil.pdf>. Acesso em: 01 jul. 2016.

Saneamento Básico: Brasil longe de atingir universalização. Saneamento Ambiental, São Paulo, 22/03/2016. Disponível em: 
<http://link.periodicos.capes.gov.br/sfxlc|41?url_ver=Z39.88-2004\&url_

ctx_fmt=fi/fmt:kev:mtx:ctx\&ctx_enc=info:ofi/enc:UTF-8\&ctx_ver=Z39.88-

2004\&rfr_id=info:sid/sfxit.com:azlist\&sfx.ignore_date_threshold=1\&rft.object_id= $1000000000808394 \&$ svc.fulltext=yes>. Acesso em: 21 jul. 2016.

Saneamento Básico: Investimento Social de Alto Impacto. Saneamento Ambiental. São Paulo, 16/05/2016. Disponível em:

$<$ http://link.periodicos.capes.gov.br/sfxlcl41?url_ver=Z39.88-

2004\&url_ctx_fmt=fi/fmt:kev:mtx:ctx\&ctx_enc=info:ofi/enc:UTF-

8\&ctx_ver=Z39.88-

2004\&rfr_id=info:sid/sfxit.com:azlist\&sfx.ignore_date_threshold=1\&rft.object_id= $1000000000808394 \&$ svc.fulltext=yes>. Acesso em: 21 jul. 2016.

SOUZA, M. M. de; SANTOS, A. S. P. Água potável, água residuária e saneamento no Brasil e na Holanda no âmbito do Programa de Visitação Holandês - DVP: Dutch Visitors Programme. Engenharia Sanitária e Ambiental. v. 21 n.2, Rio de Janeiro, abr./jun. 2016. Disponível em:

<http://www.scielo.br/scielo.php?script=sci_arttext\&pid=S1413-

41522016000200387\&Ing=en\&nrm=iso>. Acesso em: 22 jul. 2016. 